\title{
Assessment of Flood Preparedness Level in Ga-West District of Accra, Ghana
}

\author{
Samuel Amutty \\ Institute for Environment and Sanitation Studies, University of Ghana. Box LG 209, Legon, Accra
}

The research was self-financed.

\section{Abstract}

In response to increasing flood disasters and their impact worldwide, countries all over the world including Ghana, have formed disaster management institutions to help manage the flood activities and reduce their negative impacts. Despite the establishment of National Disaster Management Organization (NADMO) in Ghana to implement preparedness measures among other measures/activities to reduce the negative impacts of flood activities, subsequent flood reports in the city of Accra indicated that the impacts were rather increasing instead of reducing. The study, therefore, assessed the preparedness levels for flood disasters before the occurrence of the 2001 and 2007 flood disasters in Ga West District in Accra. Through purposive sampling, two officials, one from NADMO and Ghana Meteorological Agency (GMet), were chosen for interview. The NADMO official answered various interview questions concerning preparedness measures implemented in the study area while the GMet official answered questions regarding GMet's ability to predict heavy rainstorms that cause flood disasters ahead of their occurrence. Some household heads, mainly landlords, were also chosen through simple random sampling to respond to questionnaire regarding preparedness measures implemented by NADMO in the study area before the two flood disasters, and the various preparedness or coping strategies households adopted to reduce the negative impacts of the flood disasters on them. Direct observation by the help of photographs was also used to assess the coping strategies of households in the area. The study found that, neither NADMO nor other agencies ever carried out any preparedness measures in the study areas before the two flood disasters occurred due to resource challenges. It also became obvious that GMet possesses the capacity to predict heavy rainstorms at least 24 hours ahead before they occur and did predict the 2001 and 2007 rainstorm before the two flood disasters. But it was found out that only few people received the warning and none of these people acted on the warning. It was also obvious that households in the study area adopted various coping strategies, but they still suffered severe negative impacts of the flood disasters. The study concluded that preparedness levels in the study areas before the 2001 and 2007 flood disasters was generally very poor, hence might be responsible for the increasing incidence of flood disasters in study area and the city of Accra as a whole.

Keywords: flood preparedness measures, Household coping strategies, Negative flood disasters impacts, Flood hazard, Flood prone communities, Household preparedness strategies, Accra city.

DOI: $10.7176 / \mathrm{JEES} / 10-12-04$

Publication date: December $31^{\text {st }} 2020$

\subsection{Introduction}

The frequency and extent of flooding globally with their associated impacts are expected to increase over the next 50 to 100 years due to the effects of global warming and climate change(IPCC 2001), and other factors (Evans et al. 2004). This problem is being compounded by an ongoing rapid urbanization of cities worldwide which is making more people and properties exposed to flood hazards, hence making cities most vulnerable regions to the impact of flood hazards (Stern, 2007). In order to deal with the growing threats from floods and other disasters and their impacts, various countries in the world have set up disaster management institutions to manage them. In Ghana, National Disaster Management Organization (NADMO) was also formed in 1996 to manage disasters and similar emergencies, especially flood disasters, in order to reduce or mitigate their impacts on the vulnerable population. Among various strategies, implementation of preparedness measures/activities, in especially flood prone communities, was a key strategy to be implemented by NADMO to reduce the negative impacts of flood disasters on the vulnerable population. Implementing these measures in flood prone communities do not only prepare the community in general against flood disasters but also further enhance individual preparedness planning, and for that matter, household coping or preparedness strategies and help in reducing flood impacts. Hence implementing preparedness measures and adopting household coping strategies (household preparedness strategies) in flood prone communities are renowned in reducing negative flood impacts in flood prone communities (DNDR-ESCAP, 1999; Andjelkovic, 2001). Preparedness measures, generally, refer to actions in advance to limit the impact of hazards (ISDR, 2002), while coping strategies refer to measures adopted by disaster prone communities to help manage the impact of disasters on them (Twigg et al, 2000).

Specifically, flood preparedness measures describe a wide range of activities identified and planned well ahead of occurrence of flood events, in order to reduce potential impacts on the community, economy and other resources. These activities are meant to mitigate flood risks to an acceptable and affordable level and also 
preparation of activities to cope with the residual risks (WMO/GWP 2008; ISDR, 2002). Twigg (2004),defined mitigation as any action which is taken to minimize the extent of a disaster or potential disaster. According to him, this action can take place before, during or after a disaster. But the term is normally used to refer to action against potential disaster such as flood defense or strengthening building, training in disaster management, regulating land use and public education. According to Twigg et al (2000), preparedness and mitigation activities can all take place at any time before, during or after a disaster. That is why mitigation and preparedness are sometimes used interchangeably because they are intertwined in practice. However, mitigation normally reduces and limits the destructive and disruptive effects of flood hazards on elements at risk (i.e. things exposed to hazards).

Flood preparedness measures are many and range from the physical or structural engineering works like bridges, protective dikes, embankments, and safe building design to the non-structural interventions such as community risk assessment, community risk reduction planning, advocacy on disasters and development issues, legislation, early warning, preparation for evacuation and shelter, emergency operations management, vulnerability mapping, public disaster awareness and education, early-warning and evacuation systems, stockpiling relief materials and training in response skills and land use zoning( IFRC, 2002).

According to, Duivendijk (1999), in order to get the full benefits of early warning of on-coming flood, it requires that the flood warning is accurate, and that a warning is communicated to those at risk. The researchers also indicated that it is important that the warning sent must be received, understood, believed and must trigger appropriate action. In addition, the warning requires that. sufficient warning lead time must be provided for actions to be taken to reduce flood exposure (Parker et al., 2005). A research conducted by Elliot and Keggett (2002) in Lancashire (UK) in 2000, assessed receipt of flood warning and action taken and found that only a few (12) people received warning out of the 49 people flooded, but only $3(25 \%)$ of the 12 people who received warning with average lead time of four (4) hours, managed to take the necessary action. Some studies (Glantz, 2004; Handmer, 2000) also indicated that though all the above requirements for benefiting from early warning of on-coming flood may be fulfilled, there would always be individuals who are risk-informed about flood mitigation and prevention measures but fail to react to warnings because of insensitivity to risk, competing priorities or an inability to respond.

The implementation of various flood preparedness measures by local authorities in flood-prone areas, apart from preparing the community members to reduce flood disasters impacts on them (DNDR-ESCAP, 1999; Andjelkovic, 2001), are also said to enhance individual preparedness planning (Andjelkovic, 2001; Hutter, 2004) and for that matter household preparedness measures or household coping strategies, which eventually helps in reducing the impacts of flood disasters on them. The researchers also noted that, flood experience itself in an area is strongly linked to flood disaster preparedness in the area. Dorasamy et al., (2009), for instance, conducted a general survey to assess the level of preparedness towards flood disasters among Malaysians and found that before the natural disasters that occurred, about $37 \%$ of the respondents had received training to know about what to do and how to prepare themselves in the event of natural disaster or emergency and $36 \%$ did not attend any training programme to prepare themselves for disasters.

As indicated earlier, coping strategies refer to measures adopted by disaster prone communities to help manage the impact of disasters on them (Twigg et al, 2000). It is also defined as the application of indigenous knowledge in the face of hazards and other threats (Twig, 2004). Douglas (1985) (quoted in Blaikie et al., 1994) indicated that people rely on the coping strategies adopted by victims of past flood events to cope with future events with the assumption that the future event will follow similar trends as the events that happened in the past. The assumptions on which people make their decisions are, therefore, based on the knowledge that a particular risk is going to happen very soon of which people have some experience of how to cope ( Blaikie et al., 1994). According to Khurshid (2006), community coping mechanisms have begun to take the centre stage in disaster reduction discussion only the past few decades, due to the reality of increasing disaster impact, sharp deficit in supply of public goods and support system, and recognition of the strength of local capacity in coping with such impact

Coping strategies that flood prone communities adopt can be categorized into economic strategies, technological strategies; social strategies, and cultural strategies (Twigg, 2004). Khurshid (2006), also categorized coping strategies into preventative strategies and those employed during disasters. The preventative strategies involve several types of strategies including social, economic and structural strategies such as increase in plinth level, increased level of platform of tube-well before flood. The other type consist of those coping strategies employed during disasters. They include change in regular habits and livelihood pattern strategies. The researcher also indicated that an individual household or a community can adopt coping strategies to reduce flood impacts even before the disasters strike, and these are the types of strategies that are common in the areas where disasters are regular phenomenon. The focus of this study was on household coping strategies which were adopted in advance of flood disasters in the study area to reduce flood disaster impacts on the people.

Household coping or preparedness strategies/mechanisms from the foregoing definitions can simply be defined as the strategies or mechanisms individual households put in place to reduce or mitigate the impacts of flood disasters on their households. These household coping strategies are also said to help reduce the impact of 
floods in flood prone communities (DNDR-ESCAP, 1999; Andjelkovic, 2001). Some studies (Kreibich et al., 2005; Thieken et al., 2007), for instance, indicated that due to regular flood experiences, some households in Germany were compelled to undertake private precautionary measures against the flood disasters. These private precautionary measures were able to significantly reduce flood damage to households (ICPR, 2002; Kreibich et al., 2005). In many other countries such as the Netherlands, Italy, Japan and Bangladesh, extensive research has been done to assess households' preparedness or coping strategies for flood disasters (see Mallick et al. 2005; Motoyoshi, 2006; Takao et al. 2004; Thieken et al. 2007). Takao et al. (2004), for instance, conducted a survey on residents' awareness and preparedness to tackle floods in Nagoya City of Japan in 2002 and found that households were prepared against flood disasters but the preparedness or coping strategies were not dependent on anticipation of flood but rather on ownership of home and amount of damage experienced during previous floods.

Ghana has had its fair share of flood disasters over the years like other countries in Africa and the world at large. By way of example, floods in August and September 2007 in the three major northern regions (Northern, Upper East and Upper West) of Ghana claimed 56 lives. Furthermore, the level of destruction shows that over $500 \mathrm{~km}$ of roads was affected, 69 bridges were destroyed, 634 water bodies and dams were affected and 332,548 people were reported to be internally displaced. Also, 34,337 houses, ten schools, 51 health facilities and thousands of hactares of farm were affected (GOG, 2007)

Another flood endemic area in Ghana apart from the northern region is Accra. The capital city of Ghana, Accra, has been suffering from flood disasters resulting mainly from flash floods (sudden rising floods) since the early 1930 (Karley 2009) and have recorded series of significant flood disasters (Twumasi and Asomani-Boateng 2002; Karley 2009). These floods had wreaked much havoc in various parts of the city. Between 1955 and 1997 , for instance, property worth over US\$30 million was said to be destroyed with 100 lives lost and 10,000 people rendered permanently homeless (Gyau-Boakye, 1997).

The flood prone communities of Ga West District (Mallam, Santa Maria, Kwashiebu and Awoshie) are one of the flood prone areas which have suffered much from flood activities in the city of Accra. Though these communities are relatively new flood corridors (NADMO, 2008), they have suffered severely from many flood disasters over the years. Some of such memorable flood disasters in these communities are the 2001 and 2007 disasters. In 2007 for instance, the losses suffered by the victims in these flood prone communities during the June flood were described as quite catastrophic leading to the death of five (5) people in the study area (Ghanaian Times, 2007). These settlements are, mostly, densely populated low to middle income residential areas, dotted with series of small and medium size business enterprises. Due to the presence of the extensive Lafa Drain with numerous seasonal tributaries, the area has suffered severe flood disasters over the years. Despite the area's vulnerability to flood activities, flood researchers paid little or no attention to this area.

In view of increasing incidence of mainly flood disasters in various parts of Ghana, National Disaster Management Organization (NADMO) of Ghana was formed by Act 517 in 1996 to manage especially flood disasters and reduce their negative impacts through the application of various measures or activities. Key among such measures/activities were: preparing national disaster plan for preventing and mitigating the consequences of disasters and adopting various measures such as establishing adequate facilities for technical training and educational programmes to provide public awareness, warning systems and general preparedness for its staff and the general public(NADMO, 2005). In addition, the Government of Ghana inaugurated various statutory supervisory agencies such: as Ministry of Works and Housing, City Engineers of Accra Metropolitan Assembly and Lands Department and commissioned consultants to see to the reduction negative effects of flood disaster on human lives and properties (NEDECO, 1962; Gyau-Boakye, 1997; Adinku, 1994). Yet, subsequent reports after the formation of these institutions, especially NADMO, indicated that flood impact have increased (Government of Ghana 2001; 2003) over the years instead of reducing. According to NADMO (2009), for instance, the cost of flood damages increased from US\$500,000 to US\$1 million in the city of Accra from 2007 and 2008 respectively, representing $100 \%$ increase, which definitely included the negative impact of the catastrophic flood disaster experienced in Ga West District in 2007

In the mist of reports of increasing negative impacts of flood activities in Accra and for that matter, the flood prone communities of Ga West District, NADMO's main measure or activity in managing flood disasters, as mostly evident in the mass media, was providing emergency relief items to flood victims after the occurrence of flood disasters. However, little or no information was available on the implementation of flood preparedness measures by NADMO or other agencies in study area to prepare them against flood hazards. This, situation cast doubt on whether NADMO was implementing preparedness measures/activities to prepare the people in the flood prone communities against flood disasters and also whether households adopted coping strategies or preparedness measures against flood disasters in these communities. Yet there was little or no research in the local literature that assessed the community preparedness level against flood hazards and households coping strategies adopted against flood hazards in the flood prone communities in Ga West District, a gap this study was conducted to fill.

Knowledge on flood preparedness level in flood prone communities in Ga West District will improve the way in which internal and external actors understand flood risk and take decisions about risk management and urban 
planning (Peters et al., 2009). Indigenous knowledge of coping strategies household adopted against flood hazards in the study area would also provide useful information for planners and policy makers on the planning and policy setting for more viable disaster mitigation and response measures. Knowing the local coping strategies can also help external actors such as local government and NGO's in determining the more appropriate type of interventions and avoid undermining people's capacities (de Dios \& Honorio, 2002).

The purpose of this study was, therefore, to assess the level of preparedness for flood disasters in the flood prone communities of Ga West District of Accra before 2001 and 2007 flood disasters. Specifically, the study aimed at: i) assessing the preparedness measures implemented in flood prone communities in Ga West District against flood before the 2001 and 2007 flood disasters. ii) assessing coping or prepardness strategies households adopted in flood prone communities in Ga West District against flood before the 2001 and 2007 flood disasters.

\subsection{Material and Methods}

\subsection{Study Area}

Ga West District was chosen as the study area through informal conversation with some key officials of NADMO, based on the fact that it has some flood prone communities in Accra that are relatively recent flood corridors which has suffered severely from flood disasters, but with little focus from researchers

Ga West District is part of an urban agglomeration, often referred to as the Greater Accra Metropolitan Area (GAMA) which is coterminous with the city of Accra. The District is located in the Greater Accra Region of Ghana. It is the second largest of the six Districts in Greater Accra Region. It lies within latitude 5048'North, 5029'North and longitude 008' West and 0030'West, and shares common boundaries with Ga East and Accra Metropolitan Assembly to the East, Akwapem South, Suhum Kraboa Coalter and West Akim to the North, Awutu Efutu Senya to the West, and the Gulf of Guinea to the South. It carries a land area of approximately $710.2 \mathrm{sq} \mathrm{km}$ (Ga West District Assembly, 2004). The land area consists of gentle slopes interspersed with plains in most parts and generally undulating at less than 76m above sea levels. (Ga West District Assembly, 2004)

The District Accommodates the Lafa Drain. Lafa is one of the seven natural drainage system found in GAMA. The Lafa drain is a very extensive drain with numerous seasonal tributaries. It stretches from Sowutuom/Chantan and drains parts of Kwashiebu, Santa Maria, Anyaa, Awoshie, Gbawe, Mallam and parts of Dansoman and finally joins the sea around Panbros area. The Lafa is not lined at the moment and most portion of the Lafa drain is found in Ga West District (Watertech, 2004). Figure 2.1 and 2.2 below shows the the map of Ga West District and Lafa drainage basin respectively

\subsection{Source of data}

The study depended basically on primary data. The instruments employed in the collection of the primary data were questionnaire survey, structured interview and personal direct field observation backed by photographs.

\subsection{Sampling Procedures}

Purposive sampling was used to sample four (4) communities (Kwashiebu, Santa Maria, Awoshie and Mallam) in Ga West District which have experienced relatively severe flood activities. Since not all the areas in the chosen communities suffered flooding, 200 household heads, mainly landlords/ladies, which have suffered in both 2001 and 2007 flood disasters, were purposively identified to provide a sample frame a year after the 2007 flood disaster. The 2001 and 2007 flood disasters were chosen because they were known in the area, at the time, as the most memorable and disastrous floods. A sample size of 120 household heads was then randomly chosen with 30 from each of the four communities. Furthermore, a key informant each from NADMO and Ghana Meteorological Agency (GMet) was also purposively chosen to provide relevant information for this research.

\subsection{Research Instruments}

\subsubsection{Household Survey}

Thirty (30) flooded household heads in each of the four communities were sampled using simple random method to respond to questionnaires which were administered by the researcher aided by a colleague for a month. A household is simply defined as a person or group of persons who live together, share the same living arrangements and consider themselves a single unit (Ghana Statistical Services 2005). Though in terms of population the communities are varied, equal samples were taken from the chosen communities (table 2.1) because the actual areas in each community which suffered from the flood disasters were almost similar in size (Fig 2.2). Respondents were asked to focus on their 2001 and 2007 flood experiences in responding to the questionnaire. The questionnaire was used to assess the preparedness level of the flood prone community members before the two floods and to explore coping strategies of households before the occurrence of the devastating flood disasters in Ga West District. 2.4.2 Interviews

One official each from NADMO and GMet was purposively selected because of their specialized knowledge of the subject matter of this study. The NADMO official was asked about the preparedness measures undertaken in 
the flood prone communities of Ga-West District to prepare residents against devastating impacts of the 2001 and 2007 flood disaster in order to assess their preparedness level. GMet official was also interviewed about GMet capability to forecast the weather (extreme rainfall) before rainstorms occur, the duration of the forecast before rainstorms, whether they could determine the specific area to be affected, the mode of dissemination of forecast information and the factors that affect response to weather forecast. These questions were to assess early warning of extreme/heavy rains, and its effectiveness in the study area

2.4.3 Direct Field Observation

The various types of coping strategies households adopted before the 2001 and 2007 flood disasters in the various communities to mitigate or reduce their impacts were also explored through direct field observation backed by photographs.

\subsection{Analysis and Expected Output}

SPSS was used to produce simple descriptive statistics (frequency tables) to help analyze the responses from respondents to the questionnaire and draw inferences from the study. The frequency tables were used to analyze responses to the questionnaire on preparedness level and coping mechanism of households. Photographs were also used to back the coping strategies adopted in the study area before the flood disasters. The interviews from the two key informant were also narrated and inferences drawn from them.

\subsection{Results and Discussion}

\subsection{Introduction}

This study assessed the preparedness level for flood disasters in flood prone communities of Ga West District before 2001 and 2007 flood disasters. Specifically, it assessed the preparedness measures implemented in the flood prone communities to prepare residents to respond to flood disasters and the coping strategies households adopted in these communities against flood disasters. Having good knowledge on flood preparedness level in flood prone communities like Ga West District will improve the way in which internal and external actors understand flood risk and take decisions about risk management and urban planning (Peters et al., 2009). Moreover, the availability of indigenous knowledge of coping strategies household adopted against flood disasters in flood prone communities such as communities of Ga West District would also provide useful information for planners and policy makers on the planning and policy setting for more viable disaster mitigation and response measures (de Dios \& Honorio, 2002).

\subsection{Flood Disaster Interventions in Ga-West District}

\subsubsection{Preparedness Measures Implemented by Public Authorities}

3.2.1.1 National Disaster Management Organization and Related Agencies

NADMO is the lead public agency or authority in Ghana with the assignment of coordinating both local and international agencies in disaster management field in managing disasters especially flood disasters, to reduce their negative impact on vulnerable communities.

When the NADMO official was asked in an interview whether residents in the flood prone communities in Ga West District were taken through the various preparedness measures such as educations and training before the 2001 and 2007 flood disasters, it became obvious that apart from the occasional sensitization and education programme NADMO undertakes on national television and radio station, no such education and training ever took place in the area by NADMO or any other agency. When asked the reasons for the lack of flood preparedness measures in the area, it became evident that though NADMO had plans to educate and train flood prone residents in various preparedness activities, and further establish disaster volunteer groups in each community to continue preparing residents against flood disasters, they were unable to do so due to lack of financial resources.

A survey of household heads (table 3.2.1) also shows that all (100\%) of the respondents surveyed were never taken through any form of education and training by NADMO or any other related agencies about how to prepare for and handle flood hazards in their area before 2001 and 2007 flood disasters. This response confirmed the confession of the NADMO official about NADMO's inability to organize educational and training programmes to prepare flood prone residents as expected, due to lack of financial resources.

Inferring from the responses of the NADMO official to the interviews and all respondents from the flood prone communities of Ga West District, it is clear that the residents never received any disaster preparedness education and training from NADMO or any other agencies on how to manage flood hazards before the occurrence of the 2001 and 2007 flood disasters in the study area. There was, therefore, a general lack of official education and training in preparedness measures for flood disasters in the study area before the two flood disasters occurred. This finding differs from what pertained in Malaysian flood prone communities where, according a research conducted by Dorasamy et al. (2009), at least $37 \%$ of the household surveyed received training on what to do before during and after disaster strikes, even though some $36 \%$ of the household also did not receive any training.

This finding implies that the flood prone communities in Ga West District were generally ill-prepared to 
respond to flood disaster before the 2001 and 2007 flood disasters. This means community preparedness and individual preparedness planning for the flood disasters were all affected since implementation of preparedness measures does not only prepare the people on community level but also on individual level(Andjelkovic, 2001; Hutter, 2004). This lack of implementation of preparedness measures in the study area might partly be responsible for the disastrous impact of the 2001 and the 2007 flood disasters in the study area. It might also be a contributing factor to the increasing negative flood impacts in the city of Accra even after the formation of NADMO between 1995 and 2008(Government of Ghana 2001; 2003; NADMO, 2009).

The finding also exposed NADMO's inability in achieving one of its core mandates of preparing the flood prone communities against flood disasters in order to reduce negative flood impacts on their lives and property. This would help government and other appropriate agencies in the disaster management field to appreciate NADMO's need for more financial resource allocation for flood disaster management, especially for implementation of preparedness measures against flood disasters in flood prone areas.

3.2.1.2 Ghana Meteorological Agency

The Ghana Meteorological agency is a public authority in Ghana responsible for the forecast of weather elements in Ghana. Since the city of Accra is mostly affected by flash flood, they are responsible for forecasting any impending heavy rainstorm rather than on-coming flood, that is potentially dangerous to the public, particularly flood prone communities, for appropriate action.

Interrogating GMet's ability to forecast impending heavy rainfalls, the GMet official revealed in the interview that the agency was capable of forecasting heavy rainfalls capable of causing flood disasters 24 clear hours before they occurred. However, it became clear from the interview that GMet does not have the capacity to forecast the specific areas that would be affected by the impending heavy rainstorms, though they do speculate about them. With regard to the mode of dissemination of warning about heavy rainstorms, the interviewee indicated that the forecast was normally sent to the radio and television stations in the area for further dissemination in English and local languages to the general public in order to help flood prone residents take the needed action to avoid loss of lives and property. When asked whether there were forecast of heavy rainstorms which caused the 2001 and 2007 flood disasters in the flood prone communities of Ga West District; it was revealed that there were warnings about the impending heavy rainstorms, 24 clears hours before they occurred.

It is, however, obvious( table 3.2.2) that majority (96\%) of the respondents to the questionnaire did not receive any warning about the impending rainstorms that caused 2001 and 2007 flood disasters, while only $4 \%$ received the warnings about the impending rainstorm . It is also clear (table 3.2.3) that the warning lead time available to the six (4\%) who received the warning were in the following ranges: 10 to 30 minutes $(17 \%), 30$ to 1 hour (17\%), 1 to 6hours (17\%) and 6 to 12 hours (50\%). The result (table 3.2.4) also shows that, all (100\%) the respondents who received the warning had it through their radios. However, it is obvious (table 3.2.5) that none of the few respondents (4\%) who received the warning took any action.

Responding to the question about the factors that prevent people from benefiting from the warning about on coming heavy rainstorm capable of causing disasters, GMet official mentioned some factors such as: doubt of forecast and warning due to its inability to determine the specific areas to be affected by the rainstorms, difficulties to understand the weather forecast warning message, lack of radio and TV in the home, lack of the culture to constantly watch or listen to the news, absence from the home during the day due to work and fatalistic attitude.

Inferring from the interview with the GMet official, the agency has the capacity to accurately forecast heavy rainstorms which has the ability to cause flood disasters, 24 clear hours ahead of the rain, though without the ability to specify the areas to be affected. The warnings were then sent to radio and TV stations in the area for further dissemination in local and the English languages to the general public, particularly the flood prone communities. The finding also revealed that though GMet forecast the heavy rainstorms that caused the 2001 and 2007 flood disasters in the study area, majority of the residents did not hear the warning in order to prepare and take action due to various reasons such as: doubt of forecast and warning due to its inability to determine the specific areas to be affected by the rainstorms, difficulties to understand the weather forecast warning message, lack of radio and $\mathrm{TV}$ in the home, lack of the culture to constantly watch or listen to the news, absence from the home during the day due to work and fatalistic attitude. This finding is similar to the research conducted by Elliot and Keggett (2002) in Lancashire (UK) in 2000, where only a few (12) people received warning out of the 49 people flooded for various reasons.

The finding also revealed that the few who received warning about the impending heavy rainfall, with majority (67\%) having good lead times between one(1) hour and twelve(12) hours, also did not take any action to avoid the negative impact of the flood disasters. This finding also differs slightly from the research by Elliot and Keggett (2002) in Lancashire (UK) in 2000, where at least 3(25\%) of the 12 people who received warning out of the 49 people flooded, with average lead time of four (4) hours, managed to take the necessary action. This finding also reinforces the research conducted by Handmer( 2000) and Glantz(2004) which stated that there would always be individuals who are risk-informed about flood mitigation and prevention measures but fail to react to warnings because of insensitivity to risk, competing priorities or inability to respond. 
It is clear from the above analysis that though GMet had constantly given out warning about impending heavy rainstorms to prepare the public, especially flood prone residents against flood disasters, the goal of the forecast has not been effectively achieved. For instance, though the warning about the heavy rainfall in 2001 and 2007 were disseminated to the public, majority $(96 \%)$ of the respondents did not hear the warning in the study area, and the few who received the warning did not take any action. This might be attributed to several reasons such as not receiving warning sign, not understanding the signs, not believing the warning signals, not taking action and no sufficient lead time. This is because, getting full benefit of warning, according to Duivendijk (1999) and Parker et al., (2005), requires that the warning sent are received, understood, believed, trigger appropriate action and have sufficient lead time.

This finding is important because it would inform the government about the challenges confronting the operation of the GMet and help them know how to improve upon it. For instance, it has brought to the fore the need to educate flood prone residents about the need to listen to news always, take weather forecast of heavy rainfall very seriously and take action to avoid suffering catastrophic impact of flood disasters.

3.2.2 Coping Mechanisms Adopted by Households against Flood Disaster.

The adoption of household coping strategies has been known to be one of the key strategies for reducing negative flood impact (DNDR-ESCAP, 1999; Andjelkovic, 2001) in flood prone areas.

As seen from the table (table 3.2.6), the commonest household coping strategies adopted by households in advance against flood disasters in the study area to reduce negative flood impact on them were: raised door thresholds followed by fence walls, shelves in rooms and tall tables. These were also assessed through personal direct observations backed by photographs as evident in plates 3.1, 3.2 and 3.3

It is also obvious (table 3.2 .1 ) that, $93 \%$ of the respondents in the study area used raised door thresholds, with 93\% use in Mallam, 93\% use in Kwashibu, 87\% use in Santa Maria and 100\% use in Awoshie. As can be seen from the table (table 3.2.6), the use of fence walls was more prevalent in Santa Maria (67\%) followed by Mallam (57\%), Kwashibu (53\%) and Awoshie (50\%). Shelves in rooms were also more common in Awoshie (83\%) than in all the other communities followed by Kwashibu (27\%), Mallam (14\%) and Santa Maria (4\%). The use of tall tables which is the fourth mostly used strategy in the study area were only moderately used in the following order of importance: Santa Maria (47\%), Kwashibu(37\%), Awoshie (27\%) and Mallam (10\%).

Among the household coping strategies adopted in advance of the flood disasters in the study area, it is obvious (table 3.2.6) that the raised door threshold strategy is the commonest (93\%) strategy in the study area. It is followed by fence walls (57\%), shelves in rooms (32\%), and tall tables (30\%) being the least used strategy. It is also clear from the same table that raised door threshold strategy is the most prevalent coping strategy in Awoshie community, followed by shelves in rooms, fence walls and tall tables. In the case of Mallam, the use of the coping strategies is found in the following order of importance: raised door thresholds, fence wall, shelves in rooms and tall tables. The situation in Mallam was not any different from that of Kwashiebu in terms of order of usage of the coping strategies. In Santa Maria, however, though raised door threshold and fence walls also follow each other as in other communities, the use of tall table was found to be more prevalent here than shelves in rooms in this community unlike other communities.

It is clear from the above that, before the 2001 and 2007 flood disasters, various structural coping strategies were adopted in advance by households in various combinations in the flood prone communities of Ga West District, with each household using at least a combination of two coping strategies to reduce food impacts. This research reinforces the study conducted by Takao et al. (2004), which surveyed residents' awareness and preparedness to tackle floods in Nagoya City of Japan in 2002 and found that households were prepared against flood disasters or adopted coping strategies against flood disasters before they happened for various reasons. It also reinforces a research conducted by Kreibich et al. (2005) and Thieken et al. (2007) in Germany which found that regular flood experience forced households in flood prone areas to adopt private precautionary measures against flood

These strategies were adopted in these flood prone communities before the flood disasters probably because of the regular flood phenomenon in the study area, as indicated by Khurshid (2006), who said where flooding was a common phenomenon, advance coping strategies were adopted before the disasters struck. These various structural household coping strategies adopted before the 2001 and 2007 flood disasters in the study area might be based on traditional flood knowledge available in the local communities from people's past flood experience which guided them according to Douglas (1985) (quoted in Blaikie et al., 1994). However, it became clear that despite the various household coping strategies adopted, the impact of the 2001 and 2007 flood disasters on households in the communities in the study area were still catastrophic. This situation brought to questions the effectiveness of the coping strategies adopted by households in the study area. Yet the scope of this study did not cover the question of effectiveness of the household coping strategies.

Furthermore, since the study area is a relatively new flood corridor, the various combinations of the coping strategies adopted by a household were most probably dependent on the resources available to each household and not so much on experience and value system as indicated by Khurshid (Khurshid, 2006). This means the various 
combinations of coping strategies households adopted in the study area before the two flood disasters were more likely dependent upon the financial resources available to each household. They might also be dependent on the perception of the households about the effectiveness of the coping strategies in mitigating flood impact, and also probably on the cost of construction of the coping mechanisms. These factors might be the major factors explaining the pattern of use of household coping strategies in the various flood prone communities in Ga West District. However, the scope of this study again did not look at the factors that determined the adoption of various household coping strategies in the study area

Knowledge about the effectiveness of each of the household coping strategies adopted in advance against the flood disasters and the factors that determined the adoption of the various combinations of the coping strategies deserve critical analysis to understand the pattern of the household coping strategies used in the study area. Future research, therefore, could investigate the effectiveness of each household coping strategy in reducing flood impacts on households and the factors that influence the adoption of various household coping strategies in the study area.

\subsection{Conclusion}

The purpose of this study was, to assess the level of preparedness for flood disasters in the flood prone communities of Ga West District of Accra before 2001 and 2007 flood disasters. Specifically, the study assessed the preparedness measures implemented in flood prone communities in Ga West District before the 2001 and 2007 flood disasters. It also assessed coping strategies households adopted in Ga West District before the two flood disasters to reduce their impact on them.

The study found out that flood preparedness measures or activities meant to sensitize, educate and train the flood prone communities in Ga West District to adequately prepare them against flood disasters were not implemented by NADMO or other agencies before the 2001 and 2007 flood disasters in the study area due to lack of resources. However, heavy rainfall events capable of causing flood disasters were always forecast by GMet 24 clear days ahead of the heavy rainstorm, including the heavy rainfall events which caused the 2001 and 2007 disasters in the study area. However, despite the forecast, majority of the respondents did not hear the warnings given out in order to take action, and the few that got the warning with various lead times did not also take any action in order to avoid or reduce the flood impact on them

This finding, therefore, indicated that the preparedness level for flood disaster in the flood prone communities of Ga West District before the 2001 and 2007 flood disasters was generally very poor and hence possibly contributed to the severe impact of the two flood disasters in the study area. Similar situation in the flood prone communities of the city of Accra might be partly responsible for the increasing negative impacts of flood disasters reported by some studies (Government of Ghana, 2001, 2003; NADMO, 2009) after the formation of NADMO. In the same way, poor preparedness level in the other flood prone area of the world might be a contributing factor to the reported increasing negative flood impacts globally. Hence, effective implementation of preparedness measures in flood prone areas to prepare the vulnerable people before the occurrence of any flood disasters is key to any effort in reducing negative flood impact on the people exposed to them.

In the case of household coping strategies, the different households were found to have adopted various combinations of structural coping strategies before the 2001 and 2007 flood disasters struck in the study area in order to reduce flood impacts. These were: fence wall, raised door thresholds, shelves in rooms and tall tables in rooms. But in the face of these various structural household coping strategies, the two flood disasters were still said to cause substantial havoc to households in the study area instead of reducing their negative impact. This situation raised the question of effectiveness of the coping strategies adopted by households in mitigating negative flood impact.

What this means is that, though adopting household coping strategies are known to reduce negative flood impact on households in flood prone area, the capacity of each strategy to reduce negative flood impact on households might vary. It is, therefore, very important to know the effectiveness of any household coping strategy in reducing flood impact before adopting it. The increasing negative impacts of flood disasters in the city of Accra after NADMO's formation and in other flood prone communities of the world might, therefore, not mean the absence of household coping measures, but it might simply be the issue of the effectiveness of the strategies in reducing negative flood impacts.

\section{References:}

Adinku, S.A., (1994). Disaster preparedness: A sociological study of the flood problem in the Odaw catchment in Accra. Unpublished thesis presented to Dept. of Sociology, University of Ghana.

Andjelkovic, I. (2001). Guidelines on non-structural measures in urban flood management. Paris: IRTCUD.

Blaikie, P. Cannon, T. Davis, I. \& Wisner, B. (1994). At risk: natural hazards, people's vulnerability, and disasters. London: Routledge.

de Dios Honorio, B. (2002). Participatory Capacities and Vulnerability Assessment: Finding the link between the disaster and development.[Online] Quezon City: Oxfam Great Britain-Philippine Programme, [Available 
from: https://oxfamilibrary.openrepository.com/bitstream/handle/10546/112522/participatory-capacitiesvulnerabilities-assessment-010602en.pdf;jsessionid=085D7B9281B8F47C7CDC10B042B07CDA?sequence=1 [Access 23/08/08]

Dorasamy, M., Raman, M., Muthaiya, S. \& Kaliannan, M. (2009). Disaster Preparedness in Malaysia: An Exploratory Study.[O nline] Available from:http://www.wseas.us/elibrary/conferences/2010/Penang/MMF/MMF-02.pdf (Accessed 23/11/09)

DNDR-ESCAP (Decade Natural of Disaster Reduction-Economic and Social Commission for Asia Pacific) (1999). Regional Meeting for Asia: Risk Reduction \& Society in the 21st Century, Bangkok, 23-26 February, 1999.

Duivendijk, J. (1999). Assessment of Flood Management Options[Online] Available from:

http://oldwww.wii.gov.in/eianew/eia/dams\%20and\%20development/kbase/contrib/opt173.pdf (23/08/08)

Ga West District Assembly (2004). Ga West District Assembly Brochure.

Ghana Statistical Service (2005). Ghana Living Standards Survey Report of the Fourth Round, Accra, Ghana.

Ghanaian Times (2007). 'Five died in Floods' The Ghanaian Times, pp1, 4.

Glantz, M. (2004). Early warning systems: Do's and dont's. Report of workshop, 20-23 October 2003, Shanghai, China.

Government of Ghana (2001), Town and Country Planning Department, Flood and Drainage in Accra: A situational Analysis of the June 27, 2001 Floods. Accra, Ghana.

Government of Ghana (2003). Accra Metropolitan Assembly, Greater Accra Metropolitan Area Anti Flood Committee, Operational Plans, Accra, Ghana.

Government of Ghana (2007). Joint Assessment of flood Disasters in Three Northern Regions of Ghana. Compiled by Inter-Ministerial Disaster Relief Committee and United Nations Country Team Ghana, Accra, Ghana.

Gyau-Boakye, Y. (1998). Hydrometerological Disasters in Ghana: A paper presented at an open forum at Odawna and Nima, Accra.

Handmer, J. (2000).'Are flood warnings futile? Risk communication in emergencies'. Australasian Journal of Disaster and Trauma Studies,2(2000), p14p

Heijman, A. (2004). From vulnerability to empowerment, mapping vulnerability ; disasters, development and people. In: Bankoff, G. Frerks, G. Hilhorst,D.(Eds). Earthscan, London: Sterling, VA.

Hunter, P. (2003). Climate change and waterborne and vector-borne disease. Journal of Applied Microbiology, 94 (1), 37-46

Hutter, G. (2004). Strategies of local Government to increase the preparedness of flash floods- What can we learn from high-reliability organizations. [Online] Available from: http://www2.ioer.de/recherche/pdf/2004_hutter_strategie_frc.pdf (Accessed 23/08/08)

ICPR (International Commission for the Protection of the Rhine) (2002). Nonstructural flood plain managementmeasures and their effectiveness. Koblenz, Germany: ICPR.

ISDR (2002). Living with risk: A global review of disaster reduction initiatives. Geneva: Inter-Agency Secretariat of the International Strategy for Disaster Reduction (UN/ISDR)

IFRC (2002). World disasters report 2002: Focus on reducing risk. Geneva: International Federation of Red Cross and Red Crescent Societies.

Karley, N. (2009). Flooding and Physical Planning in Urban Areas in West Africa: Situational Analysis of Accra, Ghana. Edinburgh: Heriot Watt University.

Khurshid, A. (2006). Flood disasters. Learning from previous relief and recovery operations. ALNAP/ProventionConsortium. [Online] Available from: http://www.alnap.org/publications/pdfs/ALNAPProVention_flood_lessons.pdf(Accessed $10 / 03 / 09)$

Kreibich, H., Thieken, A.H., Petrow, T., Muller, M. \& Merz, B. (2005). Flood loss reduction of private households due to building precautionary measures - lessons learned from the Elbe flood in August 2002. Natural Hazards and Earth System Science, 5 (1), pp.117-126.

National ADisaster Management Organization (2005). Annual Report Information on Disaster Reduction for the World Conference on Disaster Reduction Kobe- Hogyo, Japan, 18 - 22 January,

National ADisaster Management Organization (2008). A situational analysis of the June 2008 flood. Accra: NADMO

National ADisaster Management Organization (2009). National Disaster Management Organization News. 3 (1), $7-15$.

Netherlands Engineering Consultant "NEDECO", (1962). Preliminary Report on the feasibility of storage or diversion of Onyasia/Odaw stream, The Hague Holland.[Online] Available from: https://www.isprs.org/proceedings/xxxiii/congress/part7/1039_XXXIII-part7.pdf[

Parker, D., Tunstall, S. \& Wilson,T.(2005). Socio-economic benefits of flood forecasting and warning [Online] Available from: http://www.actifec.net/conference2005/proceedings/PDF\%20docs/Session_08_Flood_warning/Parker_Den nis.pdf (Accessed 23/08/08) 
Peters, G., McCall, M. \& Westen, C. (2009). Coping strategies and manageability: How participatory geographical information systems can transform local knowledge into better policies for disaster risk management, Disaster Studies Working $\quad$ Paper 22 [Online] Available from: http://www.abuhrc.org/Publications/Working\%20Paper\%2022.pdf (Accessed 23/08/08

Thieken, A. H., Kreibich, H., M"uller, M., \& Merz, B. (2007). Coping with floods: preparedness, response, recovery of flood-affected residents in Germany in 2002'. Hydrological Sciences Journal. 52(5), pp. 10161037.

Twigg, J., Steiner, D., Myers, M.\& Benson, C. (2000). NGO natural disaster mitigation and preparedness projects: A study of international development and relief NGOs based in the UK. London: British Red Cross Society. [Online] Available from: www.redcross.org.uk/dmp (Accessed 23/02/09)

Twigg, J. (2004). Disaster risk reduction: Mitigation and preparedness in development and emergency programming. London: Humanitarian Practice Network

Twumasi, Y. \& Asomani-Boateng, R. (2002). Mapping Seasonal Hazards for Flood Management in Accra, Ghana Using GIS. [Online] Available from: http://ieeexplore.ieee.org/xpl/freeabs_all.jsp?arnumber=1026807 [Accessed 20/10/09]

WMO/GWP (2008). Urban Risk Management. Associated Programme on Flood Management [Online] Available from: http://www.apfm.info/pdf/ifm_tools/Tools_Urban_Flood_Risk_Management.pdf (Accessed 23/08/08)

Mr Amutty Samuel Kormla was a former Student of Institute for Environment and Sanitation Studies, University of Ghana, Legon, Accra, who now works with the Ghana Education Service. He is currently Social Studies tutor at Uman Bun Hatab Junior High School and a researcher. The author was born in a small town in the Volta Region of Ghana called Tsibu Awudome on the 6th of June, 1972. He entered University of Ghana, Legon, Accra, in 2002 and obtained his Bachelor of Art degree in Geography and Resource Development in 2006. He later in 2007 enrolled for a master's degree programme at Institute for Environment and Sanitation Studies, University of Ghana, and obtained his MPhil in Environmental Science in 2011. He has some research experience in Ghana in the area of environmental hazard and climate change. His key teaching interest areas are: environmental hazard, climate change, waste management, Geographic information systems, Environmental Law and Policy, Environmental Management etc.

\section{Appendices}

Table 2.4.1 Population of the Selected Communities

\begin{tabular}{|l|c|c|}
\hline Communities & Population & Sampled Household Sizes \\
\hline Santa Maria & 10,775 & 30 \\
\hline Mallam & 7,153 & 30 \\
\hline Awoshie & 19,890 & 30 \\
\hline Kwashiebu & 7,143 & 30 \\
\hline TOTAL & 44,961 & 120 \\
\hline
\end{tabular}

Source: GSS (2001)

Table3.2.1: Training about flood management

\begin{tabular}{|l|l|l|l|l|l|}
\hline Response & Kwashibu & Santa Maria & Mallam & Awoshie & Total \\
\hline No & 30 & 30 & 30 & 30 & $\mathbf{1 2 0}$ \\
& $100 \%$ & $100 \%$ & $100 \%$ & $100 \%$ & $\mathbf{1 0 0} \%$ \\
\hline Total & $\mathbf{3 0}$ & $\mathbf{3 0}$ & $\mathbf{3 0}$ & $\mathbf{3 0}$ & $\mathbf{1 2 0}$ \\
& $\mathbf{1 0 0} \%$ & $\mathbf{1 0 0} \%$ & $\mathbf{1 0 0} \%$ & $\mathbf{1 0 0} \%$ & $\mathbf{1 0 0 \%}$ \\
\hline
\end{tabular}

Source: Fieldwork (2009) 
Table 3.2.2 : Whether Warning Was Received in 2007 or Not

\begin{tabular}{|l|l|l|l|l|l|}
\hline Response & Kwashibu & Santa Maria & Mallam & Awoshie & Total \\
\hline \multirow{3}{*}{ Yes } & 2 & 3 & 1 & 0 & $\mathbf{6}$ \\
\cline { 2 - 6 } & $6.7 \%$ & $10.0 \%$ & $3.3 \%$ & $.0 \%$ & $\mathbf{4 . 2 \%}$ \\
\hline \multirow{2}{*}{ No } & 28 & 27 & 29 & 30 & $\mathbf{1 1 4}$ \\
\cline { 2 - 6 } & $93.3 \%$ & $90.0 \%$ & $96.7 \%$ & $100.0 \%$ & $\mathbf{9 5 . 8 \%}$ \\
\hline \multirow{2}{*}{ Total } & 30 & 30 & 30 & 30 & $\mathbf{1 2 0}$ \\
\cline { 2 - 6 } & $\mathbf{1 0 0} \%$ & $\mathbf{1 0 0} \%$ & $\mathbf{1 0 0} \%$ & $\mathbf{1 0 0} \%$ & $\mathbf{1 0 0} \%$ \\
\hline
\end{tabular}

Source: Fieldwork (2009)

Table 3.2.3: Warning lead time

\begin{tabular}{|l|l|l|l|l|l|}
\hline Lead time & Awoshie & Kwashibu & Santa Maria & Mallam & Total \\
\hline \multirow{2}{*}{$\mathbf{1 0}$ to 30mins } & 0 & 1 & 0 & 0 & 1 \\
\cline { 2 - 6 } & $0 \%$ & $50.0 \%$ & $.0 \%$ & $.0 \%$ & $16.7 \%$ \\
\hline \multirow{3}{*}{$\begin{array}{l}30 \mathrm{mins} \\
\text { to } \mathbf{1 h r}\end{array}$} & 0 & 1 & 0 & 0 & 1 \\
\hline \multirow{2}{*}{$\mathbf{1 h r}$ to $\mathbf{6 h r s}$} & $.0 \%$ & $50.0 \%$ & $.0 \%$ & $.0 \%$ & $16.7 \%$ \\
\cline { 2 - 6 } & $.0 \%$ & $50.0 \%$ & $.0 \%$ & 0 & 1 \\
\hline \multirow{2}{*}{ to $\mathbf{1 2 h r s}$} & 1 & 0 & 2 & $.0 \%$ & $16.7 \%$ \\
\cline { 2 - 7 } & $100 \%$ & $.0 \%$ & $100 \%$ & 0 & 3 \\
\hline \multirow{2}{*}{ Total } & $\mathbf{1}$ & $\mathbf{2}$ & $\mathbf{2}$ & $\mathbf{2} \%$ & $50 \%$ \\
\cline { 2 - 7 } & $\mathbf{1 0 0 , 0} \%$ & $\mathbf{1 0 0 . 0} \%$ & $\mathbf{1 0 0} \%$ & $\mathbf{1 0 0 . 0} \%$ & $\mathbf{1 0 0 . 0} \%$ \\
\hline
\end{tabular}

Source: Fieldwork (2009)

Table 3.2.4: Means Warning Was Received

\begin{tabular}{|l|l|l|l|l|l|}
\hline Means of warning & Kwashibu & Santa Maria & Mallam & Awoshie & Total \\
\hline \multirow{3}{*}{ By radio } & 1 & 1 & 3 & 1 & $\mathbf{6}$ \\
\cline { 2 - 6 } & $0.27 \%$ & $0.27 \%$ & $50 \%$ & $0.27 \%$ & $\mathbf{1 0 0} \%$ \\
\hline \multirow{2}{*}{ By TV } & 0 & 0 & 0 & 0 & $\mathbf{0}$ \\
\cline { 2 - 6 } & $0.0 \%$ & $0.0 \%$ & $0.0 \%$ & $0.0 \%$ & $\mathbf{0 . 0} \%$ \\
\hline \multirow{3}{*}{ By Police } & 0 & 0 & 0 & 0 & $\mathbf{0}$ \\
\cline { 2 - 6 } & $0.0 \%$ & $0.0 \%$ & & $0.0 \%$ & $\mathbf{0 . 0} \%$ \\
\hline \multirow{2}{*}{ Others } & 0 & 0 & 0 & 0 & $\mathbf{0}$ \\
\cline { 2 - 6 } & $0.0 \%$ & $0.0 \%$ & & $0.0 \%$ & $\mathbf{0 . 0} \%$ \\
\hline Total & 0 & 0 & 0 & 0 & $\mathbf{0}$ \\
\cline { 2 - 6 } & $0.0 \%$ & $0.0 \%$ & $0.0 \%$ & $0.0 \%$ & $\mathbf{0 . 0} \%$ \\
\cline { 2 - 6 } & $\mathbf{1}$ & $\mathbf{1}$ & $\mathbf{3}$ & $\mathbf{1}$ & $\mathbf{6}$ \\
\hline
\end{tabular}

Source: Fieldwork (2009)

Table 3.2.5: Action Taken after Receiving Warning

\begin{tabular}{|c|l|l|l|l|c|}
\hline Action taken & Awoshie & Kwashibu & Santa Maria & Mallam & Total \\
\hline \multirow{2}{*}{ Did Nothing } & 1 & 2 & 2 & 1 & $\mathbf{6}$ \\
\cline { 2 - 7 } & $100 \%$ & $100 \%$ & $100 \%$ & $100 \%$ & $\mathbf{1 0 0 . 0} \%$ \\
\hline \multirow{2}{*}{ Total } & $\mathbf{1}$ & $\mathbf{2}$ & $\mathbf{2}$ & $\mathbf{1}$ & $\mathbf{6}$ \\
\cline { 2 - 7 } & $\mathbf{1 0 0} \%$ & $\mathbf{1 0 0} \%$ & $\mathbf{1 0 0} \%$ & $\mathbf{1 0 0} \%$ & $\mathbf{1 0 0} \%$ \\
\hline
\end{tabular}

Source: Fieldwork (2009) 
Table 3.2.6 Coping Strategies Adopted by Respondents against Flood Hazards

\begin{tabular}{|l|c|c|c|c|c|}
\hline \multicolumn{1}{|c|}{$\begin{array}{c}\text { Coping } \\
\text { Measures }\end{array}$} & Kwashibu & Santa Maria & Mallam & Awoshie & Total/ \% \\
\hline \multirow{2}{*}{ Shelves in rooms } & 8 & 1 & 4 & 25 & $\mathbf{3 8}$ \\
\cline { 2 - 6 } & $27 \%$ & $4 \%$ & $14 \%$ & $83 \%$ & $\mathbf{3 2} \%$ \\
\hline \multirow{2}{*}{ Tall tables } & 11 & 14 & 3 & 8 & $\mathbf{3 6}$ \\
\cline { 2 - 6 } & $37 \%$ & $47 \%$ & $10 \%$ & $27 \%$ & $\mathbf{3 0 \%}$ \\
\hline \multirow{2}{*}{$\begin{array}{l}\text { Raised door } \\
\text { thresholds }\end{array}$} & 28 & 26 & 28 & 30 & $\mathbf{1 1 2}$ \\
\hline \multirow{2}{*}{ Fence wall } & $93 \%$ & $87 \%$ & $93 \%$ & $100 \%$ & $\mathbf{9 3 \%}$ \\
\cline { 2 - 6 } & $53 \%$ & 20 & 17 & 15 & $\mathbf{6 8}$ \\
\hline \multirow{2}{*}{ Total } & $\mathbf{3 0}$ & $\mathbf{3 0} \%$ & $57 \%$ & $50 \%$ & $\mathbf{5 7 \%}$ \\
\cline { 2 - 6 } & $\mathbf{1 0 0 \%}$ & $\mathbf{1 0 0 \%}$ & $\mathbf{1 0 0} \%$ & $\mathbf{3 0}$ & $\mathbf{1 2 0}$ \\
\hline
\end{tabular}

Source: Fieldwork (2009) Multiple response

Figure 2.1: Map of Ga West District

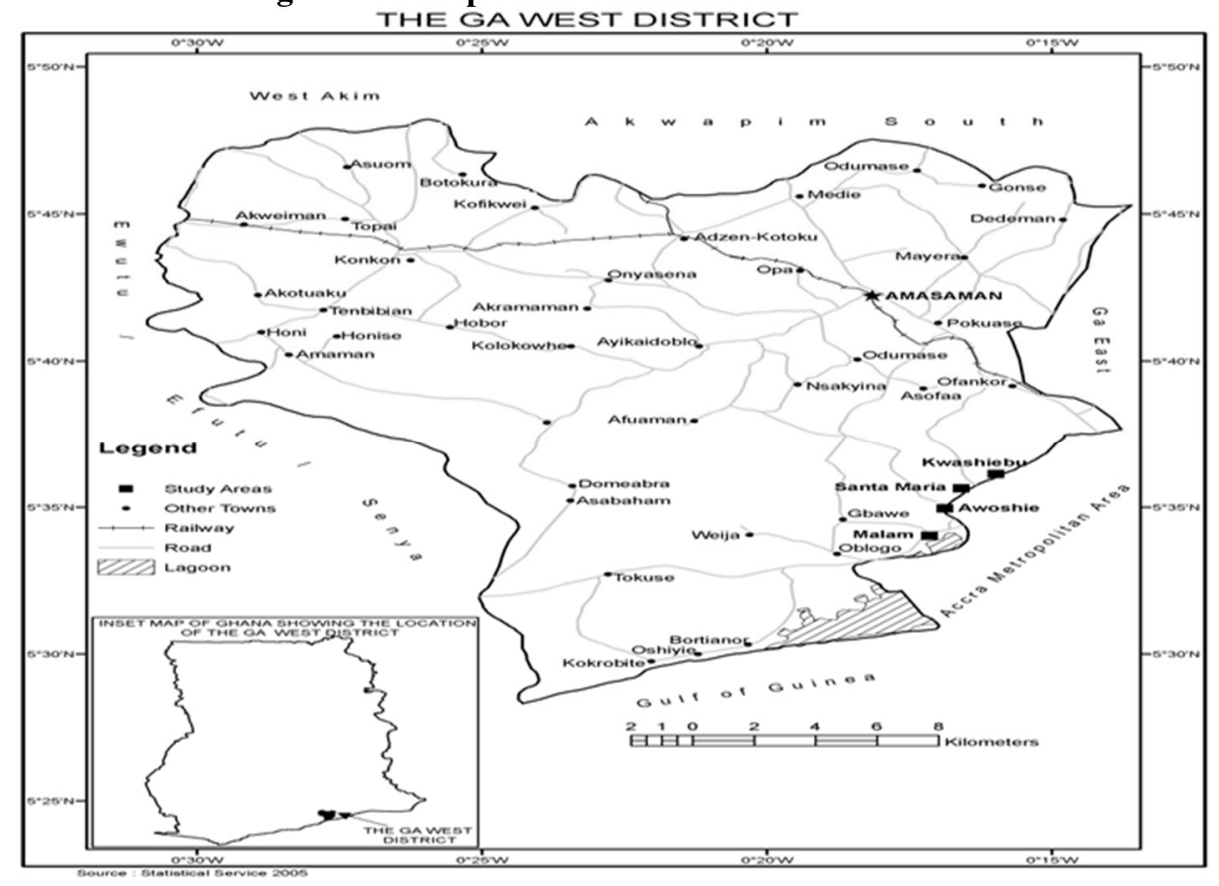

Figure 3.2: Lafa Drain

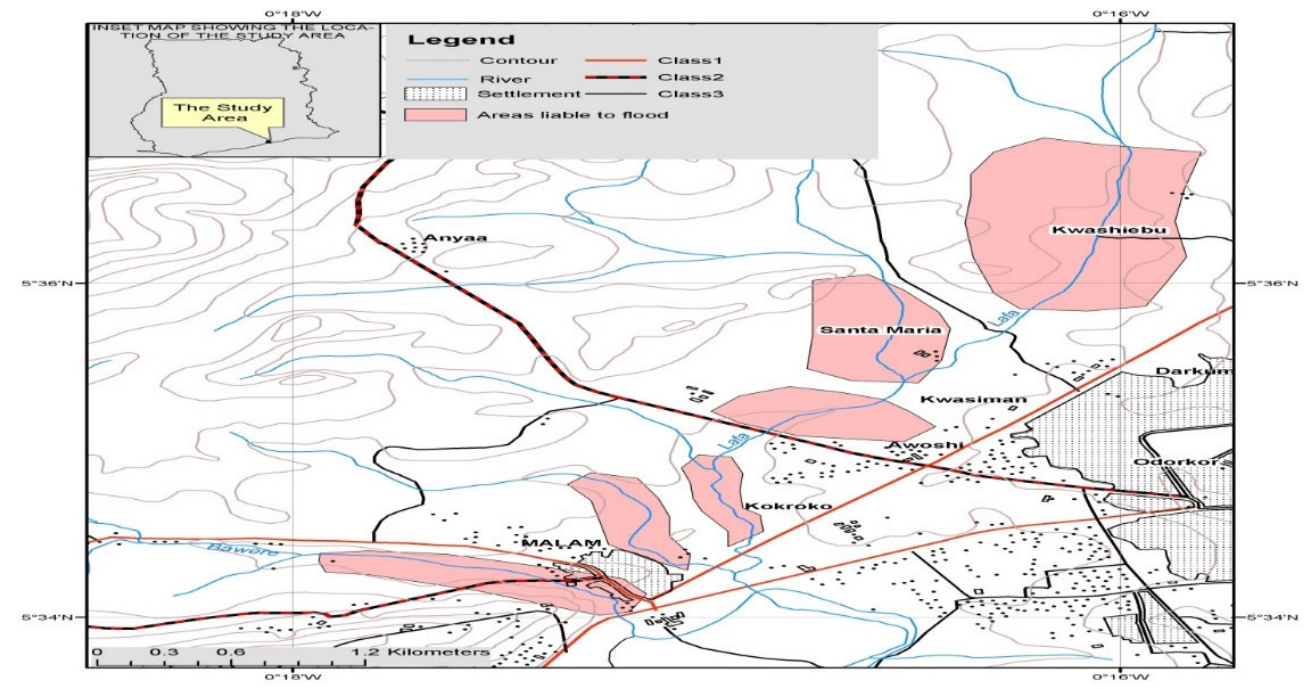




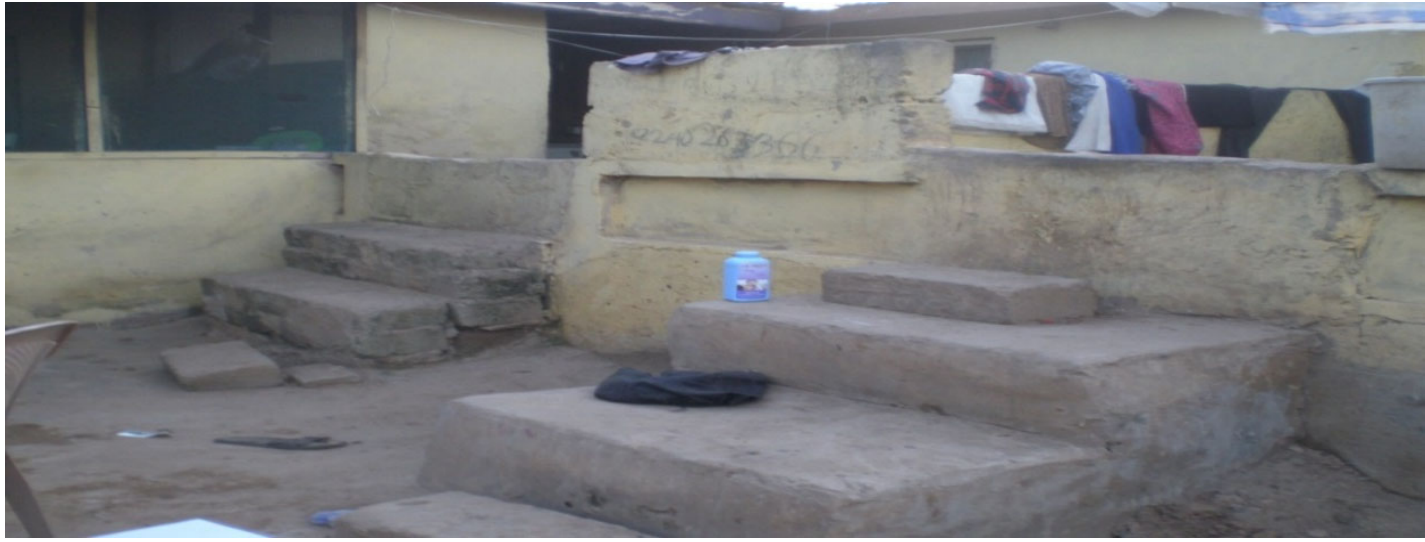

Plate 3.1: Raise Door Threshold in Awoshie to prevent flood water from room.

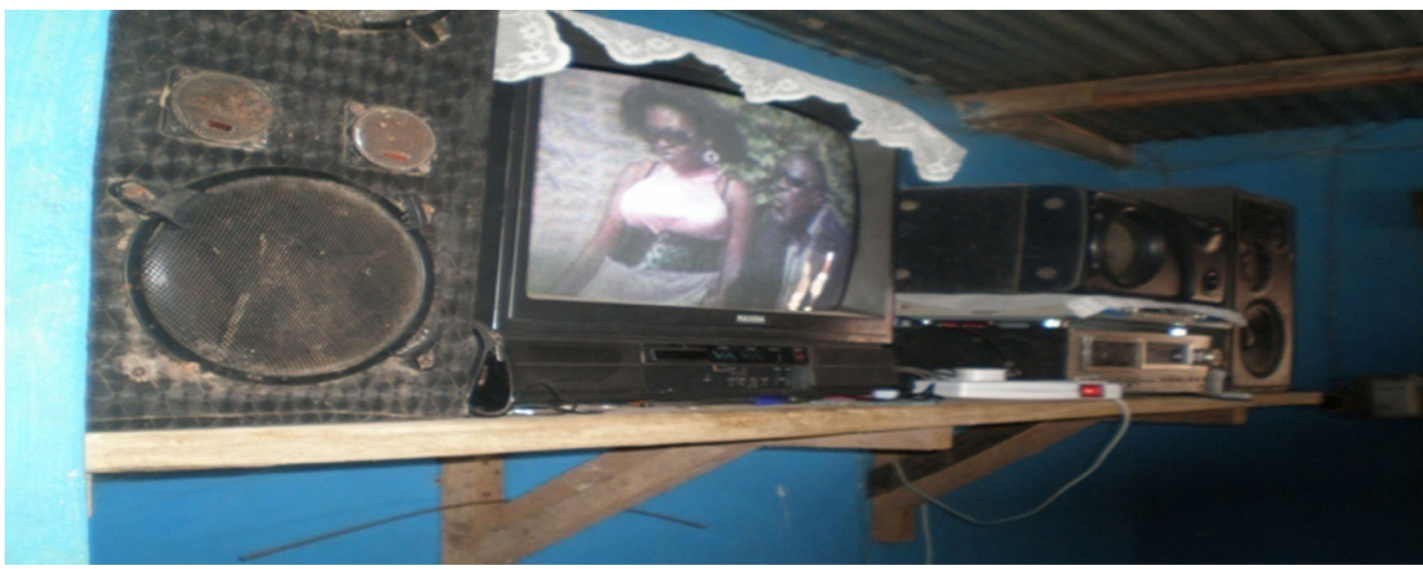

Plate 3.2: Shelf in room at Awoshie used to keep belongings above flood water

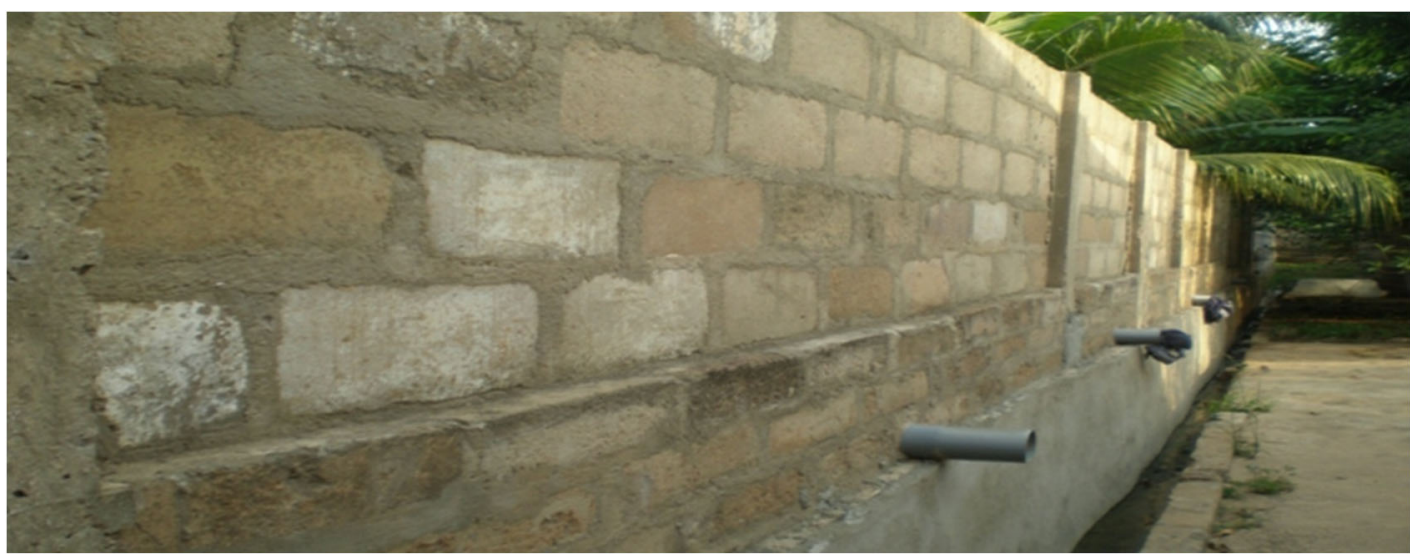

Plate 3.3: Fence wall in Santa Maria to prevent flood water from entering house. 